University of New Haven

University of

New Haven

Digital Commons@ New Haven

\title{
Freeze-thaw Durability of Concrete Columns Wrapped with FRP and Subject to Corrosion-Like Expansion
}

\author{
Ronald S. Harichandran \\ University of New Haven, rharichandran@newhaven.edu \\ M.I. Baiyasi \\ Elsinore Valley Municipal Water District \\ G. Nossoni \\ Manhattan College
}

Follow this and additional works at: http://digitalcommons.newhaven.edu/civilengineering-facpubs Part of the Civil Engineering Commons

\section{Publisher Citation}

Harichandran, R. S., Baiyasi, M. I., and Nossoni, G. (2016). "Freeze-thaw durability of concrete columns wrapped with FRP and subject to corrosion-like expansion." Journal of Materials in Civil Engineering, 29(1).

\section{Comments}

This is the authors' accepted manuscript of the article published in Journal of Materials in Civil Engineering. The version of record can be found at http://dx.doi.org/10.1061/(ASCE)MT.1943-5533.0001691\#sthash.JA9OUibt.dpuf 


\section{WITH FRP AND SUBJECT TO CORROSION-LIKE EXPANSION}

R. S. Harichandran, ${ }^{1}$ M. I. Baiyasi ${ }^{2}$ and G. Nossoni ${ }^{3}$

\section{ABSTRACT}

9 Experiments were conducted to assess the effects of using fiber-reinforced polymer (FRP)

10 wraps, with fibers oriented in the hoop direction, for rehabilitating corrosion-damaged

11 columns. This paper reports findings related to the freeze-thaw durability of concrete

12 specimens with round and square cross sections, wrapped with glass and carbon FRP, after

13 they are subjected to an internal expansive force similar to that generated by corroding steel.

14 The results of the experiment indicate that freeze-thaw cycles have no statistically significant

15 effect on the compressive strength of glass and carbon wrapped specimens. Freeze-thaw

16 conditioning generally reduced the longitudinal failure strain of wrapped specimens. The

17 square wrapped specimens had lower compressive strength compared to the round

18 specimens, even though the cross sectional area of the square prisms was higher than that of

19 the round cylinders. This is due to the reduced confinement provided by the wraps for square

20 cross sections and stress concentrations that develop at the corners. Wrapped square prisms

21 always failed by rupture of the wrap at a corner. A reduction of approximately $30 \%$ to $40 \%$

${ }^{1}$ Dean, Tagliatela College of Engineering, University of New Haven, West Haven, CT 06516.

2 Manager, Elsinore Valley Municipal Water District, 31315 Chaney St, Lake Elsinore, CA 92530

3 Asst. Prof., Department of Civil and Environmental Engineering, Manhattan College, Riverdale, NY 10471. 
22 in failure stress was noted between wrapped specimens with round and square cross sections,

23 respectively.

\section{INTRODUCTION}

26 One of the main causes of deterioration in reinforced concrete structures is corrosion

27 of the reinforcement bars ( $\mathrm{Du}$ et al. 2006). The strength, durability and service life of

28 concrete structures are reduced by corrosion. Corrosion products can have a volume of up to

$29600 \%$ of the original volume of the corroding steel (Mehta and Monteiro 1993). This extra

30 volume applies pressure to the surrounding concrete and causes cracking and delamination of

31 the concrete cover. Both oxygen and chloride is required for the corrosion activity to start. If

32 a barrier reduces the diffusion of oxygen and chloride into concrete, then the time to

33 corrosion will reduce considerably. Using FRP wraps is one way to introduce a barrier that

34 retards the diffusion of oxygen and chloride into concrete, thereby increasing the service life

35 and durability of concrete structures (Nossoni 2015).

36 FRP materials have been used over the past two decades in civil engineering

37 structures for different strengthening applications because of their superior mechanical

38 properties as well as their resistance to aggressive environmental conditions. However, some

39 environmental factors such as extreme temperature fluctuation and water absorption can

40 adversely affect the behavior of some polymer composite material. Water absorption reduces

41 the strength and stiffness of some polymeric composites by as much as $30 \%$ compared to dry

42 material. Water absorption can break down the interface between the reinforcing fiber and

43 resin matrix leading to loss of strength and rigidity. Cycles of freezing and thawing tend to

44 magnify the effect of water absorption (Gomez and Casto 1996). 
While several studies have been conducted on the strength of columns wrapped with

46 FRPs, studies on durability under harsh environmental conditions such as freeze-thaw and

47 exposure to chloride are much fewer (Soudki 1997, Toutanji and Balaguru 1998, Rivera and

48 Karbhari 1999, Almusallam et al. 2000, El-Zefzafy et al. 2011). Also, most of these studies

49 focused on the deterioration of the FRP and concrete bond rather than the behavior of the

50 FRP wrap under these harsh environments (Karbhari and Zhao 1998, Colombi et al. 2009,

51 Shi et al. 2013, Silva and Bicaia 2008, Yun and $\mathrm{Wu}$ 2011). Results from most studies

52 indicated that freeze-thaw cycling does not have a significant effect on the bond strength

53 between FRP and concrete and most of the specimens failed in the concrete substrate and not

54 along the bonded surface (Chajes et al. 1994, Colombi et al. 2009, Silva and Biscaia 2008,

55 Toutanji and El-Korchi 1999, Karbhari and Zhao 1998). However, one study found that the

56 failure was more brittle after freeze-thaw cycling (Karbhari and Zhao 1998).

57 A few studies reported the effect of harsh environment on FRP strength and the final

58 confined concrete strength of FRP-wrapped concrete specimens after exposure. Specimens

59 wrapped with CFRP experienced no reduction in strength or ductility due to wet-dry

60 exposure, whereas specimens wrapped with GFRP experienced more reduction in both

61 strength and ductility (Li and Karbhari 2003, Rivera and Karbhari and Zhao 1998, Toutanji

62 and Balaguru 1998, Steckel et al. 1998, Nardone et al. 2012). However, a study by Chin et al.

63 (1997) concluded that there was no significant reduction in the tensile strength of GFRP

64 when it was exposed to salt and distilled water for more than 1300 hours.

65 In a few studies the durability and strength of FRP-wrapped concrete columns under

66 simultaneous loading and environmental exposure was reported. Green et al. (2006) studied

67 the effect of sustained load and freeze-thaw cycles at the same time and concluded that 
68 confined concrete strength was not reduced significantly for normal strength concrete.

69 However, there appears to be no research that investigated the simultaneous effect of freeze-

70 thaw cycling and corrosion of reinforcing bars. Usually corrosion of steel bars occurs due to

71 deicing salts, and the corrosion of steel bars and freeze thaw cycles can occur simultaneously.

72 In the research reported herein, a comprehensive experimental study was performed

73 to investigate the strength of FRP-wrapped cylinders when they were subjected to a sequence

74 of different environmental exposure conditions. First, the cylinders were subjected to

75 corrosion-like expansion and then to freeze-thaw conditioning. Corrosion-induced expansion

76 was simulated using the expanding cement Bristar. The expansion due to Bristar was

77 calibrated using experiments and validated using an analytical solution and finite element

78 analysis. Subsequently, the samples were subjected to 300 freeze-thaw cycles to study the

79 effect of both conditions on the compressive strength of the confined concrete.

EXPERIMENTAL WORK

\section{Durability of FRP Panel}

82 First the effect of freeze-thaw and wet-dry cycles on the durability of two different

83 types of FRP, glass FRP (GFRP) and carbon FRP (CFRP), was investigated. Four-ply GFRP

84 and two-ply CFRP sheets were fabricated using the wet lay-up process. The samples were

85 cured in air for 5 days according to vender recommendations. After curing, the FRP panels

86 were subjected to 300 freeze-thaw cycles. Subsequently, the FRP panels were cut into

87 coupons and strain gauges were mounted on the coupons. The width of the test specimens

88 varied from 13 to $19 \mathrm{~mm}$ (0.5 to $0.75 \mathrm{in}$.) and their length varied from 190 to $230 \mathrm{~mm}$ (7.5 to

899.0 in.), depending on the test. The gage length over which strains were measured was

$9089 \mathrm{~mm}$ (3.5 in.). The test machine was equipped with hydraulically actuated wedge grips 
91 with serrated faces. The FRP coupons were tested under tension to determine the tensile

92 strength, $f_{u}$, ultimate strain, $\varepsilon_{u}$, and elastic modulus, $E$, of both the conditioned and

93 unconditioned sheets. All the tested coupons were selected from one GFRP panel and one

94 CFRP panel.

\section{Durability of Confined Concrete}

96 Sample preparation: After evaluation of the FRP panels, the effect of simultaneous

97 corrosion-like expansion and freeze-thaw cycles on the durability and strength of FRP-

98 wrapped concrete specimens was investigated. Ready mixed concrete with a water/cement

99 (w/c) ratio of 0.4 and an air entraining admixture was used. The 28-day mean compressive

100 strength of the concrete was $37.7 \mathrm{MPa}(5,468 \mathrm{psi})$. A total of 30 specimens were cast. Two

101 different types of specimens were used; round cylinders with a diameter of $152 \mathrm{~mm}$ (6 in.)

102 and a height of $305 \mathrm{~mm}$ (12 in.), and square prisms with a $152 \mathrm{~mm} \times 152 \mathrm{~mm}$ cross section

103 and a $305 \mathrm{~mm}$ height. The corners of the square prisms were rounded to a $13 \mathrm{~mm}(0.5 \mathrm{in}$.)

104 radius. Since natural or accelerated corrosion tests are time consuming, an expanding cement

105 known as Bristar was used to simulate the expansion due to corrosion of reinforcing bars.

106 Out of 30 specimens, 24 specimens (12 round and 12 square), were fabricated with a $38 \mathrm{~mm}$

107 (1.5 in.) diameter center hole in the longitudinal direction, and 6 specimens were cast as solid

108 round cylinders. The six solid round specimens without a center hole were not wrapped and

109 kept as control specimens. Solid square specimens without a center hole were not cast

110 because the strength of unwrapped concrete samples is not affected significantly by the

111 geometry of the cross section. The specimens with a center hole were wrapped with FRP and

112 then the center hole was filled with Bristar. The expansion force exerted by Bristar could be

113 controlled with the water to Bristar ratio and was calibrated using experiments, and analytical 
114 and finite element modeling. Although steel rebars were not used, chloride was introduced

115 into the concrete by mixing $11 \mathrm{~kg}$ of NaCl$/ \mathrm{m}^{3}$ of concrete, which translates to $2 \% \mathrm{Cl}^{-}$ions by

116 weight of cement (Arya and Said-Shawaqi 1996) during casting in order to simulate

117 contaminated concrete.

118 Wrapping: After 28 days of curing, out of a total of 24 wrapped specimens, 12 were

119 wrapped with three layers of GFRP and 12 with two layers of CFRP having fibers orientated

120 in the hoop direction. All wrapped specimens were subjected to expansion using Bristar one

121 week after wrapping.

122 Freeze-Thaw: After the initial expansion period of Bristar, which was about one

123 week, 15 specimens (12 wrapped and 3 unwrapped) were exposed to 300 freeze-thaw cycles

124 according to the ASTM C666 procedure and the other 15 samples were kept as control

125 specimens. Table 1 shows the number of samples in each batch.

126 Strain Gauge Placement: Strain gauges were used to monitor wrap hoop strains

127 during Bristar-induced expansion, and freeze-thaw and compression tests. Six round

128 specimens and six square specimens (three for each type of wrap) that were to undergo 300

129 cycles of freeze-thaw and four control specimen (one for each type of wrap and specimen

130 shape) were fitted with strain gauges. Each specimen was fitted with two strain gauges

131 oriented in the circumferential direction and placed opposite each other at mid-height. The

132 gauges were coated with wax and silicon to provide moisture and mechanical protection.

133 Bristar: The effectiveness of using Bristar to simulate corrosion-induced expansion

134 was initially tested on some trial specimens. The expansive nature of Bristar caused the trial

135 specimens to expand in the hoop direction as desired. However, an undesirable side effect

136 was the simultaneous expansion in the longitudinal direction. This caused the trial specimens 
137 with the carbon wrap to split across a cross sectional plane since the carbon wrap contained

138 no longitudinal fibers. The glass wrap had bidirectional fibers and the fibers in the

139 longitudinal direction prevented the specimens from splitting. Additional longitudinal

140 reinforcement was provided to the carbon-wrapped test specimens by strengthening with

$14151 \mathrm{~mm}(2 \mathrm{in}$.) wide strips of carbon in the longitudinal direction. The strips were spaced with

$14251 \mathrm{~mm}(2 \mathrm{in}$.) gaps between them around the circumference. The strain gauge readings were

143 not affected because the strips were placed adjacent to the gauges and the longitudinal strips

144 did not provide any additional lateral confinement.

\section{BRISTAR CALIBRATION}

146 The Bristar mix was used to simulate the internal pressure applied by corroding

147 reinforcing bars. The amount Bistar expands is highly dependent on the water to Bristar ratio.

148 An attempt was made to calibrate the water/Bristar ratio so that a confining pressure in the

149 FRP wraps similar to that developed by corrosion-induced expansion could be generated.

150 Experimental testing was initially performed and then analytical calculations were conducted

151 to calibrate the internal pressure of Bristar expansion to match the pressure due to corrosion

152 of steel bars resulting from a 33\% mass loss reported by Harichandran and Baiyasi (2000).

153 Later, the results were validated using finite element simulations.

\section{Experimental Testing}

155 Two concrete specimens to be used for calibration were cast in $4.77 \mathrm{~mm}$ thick steel

156 tubes having the same dimensions of a $152 \mathrm{~mm}$ diameter, $305 \mathrm{~mm}$ height, and a $38 \mathrm{~mm}$

157 center hole. Strain gauges were mounted on the steel tube to monitor its hoop strain. After the

158 concrete was allowed to cure for 28 days, Bristar was prepared with the two different

159 water/Bristar ratios of 0.4 and 0.5 and was poured into the center hole. The strains developed 
160 in the steel tubes were monitored for 9-13 days until Bristar reached its final volume and the

161 strains stabilized. Figure 1 shows the strain developed in the steel tube in the calibration

162 samples. The strain in the steel tube reached 380 microstrains $(\mu \varepsilon)$ in about 4 days for the

163 water/Bristar ratio of 0.5 and around $660 \mu \varepsilon$ in about 7 days for the water/Bristar ratio of 0.4 .

\section{Analytical Method}

165 From the mechanics of thin walled cylinders, the confining pressure in a confined

166 column is given by

$$
f_{r}=\frac{2\left(E \varepsilon_{t} t n\right)}{D}
$$

168 where $t=$ thickness of the steel tube or wrap per layer, $\varepsilon_{t}=$ circumferential strain of the tube,

$169 E=$ elastic modulus of the tube, $n=$ number of FRP or steel tube layers and $D=$ diameter of 170 the cylindrical column.

171 Using Equation 1, the confining pressures in the steel tube were estimated from the 172 maximum hoop strain in the steel tube shown in Figure 1 for the two different water/Bristar 173 ratios. The maximum confining pressures calculated using Equation 1 were $4.76 \mathrm{MPa}$ 174 (690 psi) and 8.27 MPa (1200 psi) for water/Bristar ratios of 0.5 and 0.4 , respectively, and

175 are shown in Table 2. Assuming that the same confining pressures would be developed if 176 three layers of GFRP wrap confined the specimens instead of the steel tube, the hoop strains 177 in the GFRP wrap were back calculated using Equation 1. The hoop strain in a 3-layer GFRP 178 wrap that would induce the confining pressures of 4.76 and $8.27 \mathrm{MPa}$ were estimated to be $1794,500 \mu \varepsilon$ and $7,800 \mu \varepsilon$, respectively. These hoop strains were compared with those in a 3-

180 layer GFRP wrap reported by Harichandran and Baiyasi (2000) for a 33\% mass loss resulting 181 from accelerated corrosion for 190 days. Harichandran and Baiyasi studied the effect of 
182 bonded and unbonded FRP wraps on the corrosion rate and used $152 \mathrm{~mm}$ diameter and

$183305 \mathrm{~mm}$ high concrete cylindrical specimens (the same as the calibration specimens in this

184 study), with four \#13 steel reinforcing bars placed with $13 \mathrm{~mm}$ of cover. They used two bars

185 as anodes and two bars as cathodes to keep the corrosion products within the specimens as in

186 natural corrosion. Figure 2 shows the GFRP strains reported by Harichandran and Baiyasi

187 (2000) for one specimen. The strain gauge was located at the crack location and yielded a

188 strain of about $4,000 \mu \varepsilon$. Comparing this strain with the GFRP wrap hoop strains of 4,500 $\mu \varepsilon$

189 and $7,800 \mu \varepsilon$ for the water/Bristar ratios of 0.4 and 0.5 , respectively, calculated from

190 Equation 1, the water/Bristar ratio of 0.5 appeared appropriate for the experimental study.

\section{Numerical Validation}

192 The analytical model assumes that the expanding Bristar causes the same confining

193 pressure to be applied by the steel tube and GFRP wrap. This assumption is inaccurate

194 because the stiffness of steel and GFRP is different. The GFRP wrap will expand more than

195 the steel tube resulting in a lower confining pressure. A finite element model can capture this

196 behavior and was used to verify whether the water/Bristar ratio of 0.5 was indeed appropriate

197 for the experimental study.

198 The general-purpose FE program ABAQUS (Version 6.12) was used. First, an FE 199 model of the calibration specimen with the steel tube and the center hole was analyzed. In the

200 FE analysis, a uniform radial pressure was applied to the inside surfaces of the center hole of 201 the round calibration specimens to simulate the pressure exerted by expanding Bristar. Since 202 the round calibration specimens were radially symmetric, only one quarter of the specimens 203 was modeled in the FE analysis and appropriate boundary conditions were applied (i.e., free 204 movement of boundary nodes in the radial and longitudinal directions). The insets in Figures 
2053 and 4 show the finite element meshes used. The material models used in ABAQUS are 206 described below.

207 Concrete: The Drucker-Prager plasticity model in ABAQUS was used to model the 208 behavior of the confined concrete. The main parameters of the model, such as dilation and 209 friction angles, were selected from the literature ( $\mathrm{Yu}$ et al, 2010). Other parameters of the

210 model included the concrete compressive strength and elastic modulus, which were obtained

211 through laboratory testing and the $\mathrm{ACI}$ equation (i.e., $E_{C}=4700 \sqrt{f^{\prime}} \mathrm{MPa}$ ), respectively, 212 and are listed in Table 3.

213 Steel Reinforcement: The steel tube in the calibration specimen was modeled as an 214 isotropic elastic-perfectly plastic material. The parameters required for the material model 215 were elastic modulus, yield strength and Poisson's ratio, and the values selected from the 216 literature are shown in Table 3.

217 FRP Material: The orthotropic linear elastic material model with the Lamina option 218 was used to model the GFRP wrap used by Harichandran and Baiyasi (2000) in their 219 accelerated corrosion test specimens. Model parameters such as the elastic and shear moduli 220 in all directions and Poisson's ratio were selected based on the mechanical properties 221 provided by the manufacturer and are shown in Table 3.

222 Concrete Interface: The interfaces between the concrete/steel tube and 223 concrete/GFRP wrap were assumed to be fully bonded. Full bonding between the surfaces 224 was achieved by using the tie option in ABAQUS.

225 The internal radial pressures that caused the same hoop strains in the steel tube as in 226 the experimental specimens for the water/Bristar ratios of 0.4 and 0.5 were estimated.

227 Figure 3 shows how the strain in the steel tube in the FE model of the calibration specimens 
228 changes with the radial pressure applied to the inside of the center hole. The pressures

229 causing strains of $380 \mu \varepsilon$ and $660 \mu \varepsilon$ in the steel tube were estimated to be $22 \mathrm{MPa}$ and

$23025.5 \mathrm{MPa}$, respectively. These pressures correspond to those that Bristar with water/Bristar

231 ratios of 0.5 and 0.4 applies to the surrounding concrete in the calibration specimens,

232 respectively. These pressures were then applied in the FE model of the calibration specimens

233 with three layers of GFRP wrap and the strains in the wrap were compared with the strain of

234 about 4,000 $\mu \varepsilon$ measured in the GFRP wrap by Harichandran and Baiyasi (2000). Figure 4

235 shows the relationship between the internal radial pressure and the GFRP wrap strain in the

236 FE simulations. The strains in the GFRP wrap due to the internal radial pressures of $22 \mathrm{MPa}$

237 (corresponding to water/Bristar ratio of 0.5 ) and $25.5 \mathrm{MPa}$ (corresponding to a water/Bristar

238 ratio of 0.4$)$ were $3,800 \mu \varepsilon$ and $5,000 \mu \varepsilon$, respectively. As expected, the analytical model was

239 inaccurate and the hoop strains in the GFRP wrap from finite element simulations are lower

240 than those computed by the analytical method. Nevertheless, the FE analysis confirms that

241 the water/Bristar ratio of 0.5 is appropriate to simulate corrosion-induced expansion because

242 the predicted GFRP strain of $3800 \mu \varepsilon$ is close to the peak strain of $4,000 \mu \varepsilon$ measured by

243 Harichanandran and Baiyasi (2000) for 33\% of mass loss in their accelerated corrosion test.

\section{RESULTS AND DISCUSSION}

\section{Durability of FRP Panel}

247 Table 4 lists the mechanical properties of the FRP panels before and after freeze-thaw

248 exposure. Note that different sets of specimens were used for the unconditioned modulus and

249 strength tests. It was difficult to control the thickness of panels fabricated using the wet lay-

250 up process and the mechanical properties of the FRP panels are sensitive to specimen 
251 thicknesses. To avoid this sensitivity, the effective stiffness (i.e., modulus $\times$ thickness) and

252 ultimate strength per unit width (i.e., ultimate strength $\times$ thickness) were used to compare 253 results.

254 Figure 5 and Table 4 indicate that freeze-thaw conditioning had little effect on the 255 mean effective stiffness of glass panels, while for carbon panels it appears to have increased 256 by $30 \%$, the latter being significant at the $95 \%$ level. The decrease of $21 \%$ in the mean 257 ultimate strength per unit wideth of glass is significant at the $95 \%$ level, but the apparent 258 increase in strength for carbon is not significant at the $95 \%$ level (because of the large

259 variation for the unconditioned panels). The decrease of $20 \%$ and $28 \%$ in the mean ultimate 260 strains of glass and carbon panels, respectively, is significant at the $95 \%$ confidence level. It 261 should be noted that many of the failures occurred at the grips and may have been premature.

262 The ultimate strains of the unconditioned and conditioned specimens are significantly lower 263 than the values reported by the manufacturer.

\section{Durability of Confined Concrete}

265 Strength and durability tests were performed on FRP-wrapped round and square 266 cylinders. The primary purpose of the tests was to determine the durability of the FRP tubes

267 under simultaneous corrosion and freeze-thaw cycling, with strength considerations being 268 secondary.

269 Corrosion expansion: Initially, the expansion due to accelerated corrosion for 190 270 days causing $33 \%$ mass loss was simulated using Bristar. Based on the calibration results 271 reported earlier, the water/Bristar ratio was selected to be 0.5 .

272 Initial strain gauge readings from the FRP wrap were taken prior to pouring Bristar in 273 the center hole of each specimen. Since Bristar is highly porous and water absorption with 
274 subsequent freezing and thawing within the hole containing Bristar was undesirable, the ends

275 of the specimens were coated with epoxy prior to the freeze-thaw tests after the Bristar had

276 fully expanded.

277 The average strain in the wraps after adding Bristar varied from 3,100 to $6,000 \mu \varepsilon$ for

278 GFRP-wrapped specimens with an average of $4,700 \mu \varepsilon$ and 2,400 to $6,800 \mu \varepsilon$ for CFRP-

279 wrapped specimens with an average of $4,800 \mu \varepsilon$. Variations in these values occurred because

280 it was not possible to control the pressure exerted by Bristar precisely. However, the average

281 strain values were a little higher than the strain of $4,000 \mu \varepsilon$ measured by Harichandran and

282 Baiyasi (2000) in the GFRP wrap due to steel corrosion and 33\% mass loss (see Figure 2)

283 and the predictions of $4,500 \mu \varepsilon$ and $3,800 \mu \varepsilon$ from the analytical and FE models. As shown in

284 Figures $6 \mathrm{a}$ and $6 \mathrm{~b}$, the round specimens had lower strains (average of $3200 \mu \varepsilon$ ) that were

285 closer to the FE predictions compared to the square specimens because the Bristar calibration

286 was done using round specimens.

287 Freeze-Thaw Test: After corrosion-like expansion of wrapped specimens, they were 288 subjected to freeze-thaw cycles according to the ASTM C666 Procedure B, with freezing in 289 air and thawing in water. Thermocouples mounted at the center of wrapped and unwrapped 290 control specimens were used to measure the internal temperatures during testing. Since the

291 wrapped specimens took longer to reach $-17.8^{\circ} \mathrm{C}$ (end set point for the freeze cycle) and $2924.4^{\circ} \mathrm{C}$ (end set point for the thaw cycle) than the unwrapped specimens, the freeze-thaw 293 machine was precisely calibrated before the test. ASTM C666 allows a tolerance of $\pm 1.7^{\circ} \mathrm{C}$ at

294 the upper and lower set points. By adjusting the sump water temperature during a few trial 295 cycles, it was determined that a sump water temperature of $7.2^{\circ} \mathrm{C}$ would ensure that all 
296 specimens attained temperatures of $-17.78 \pm 1.7^{\circ} \mathrm{C}$ at the end of the freeze cycle and

$2974.4 \pm 1.7^{\circ} \mathrm{C}$ at the end of the thaw cycle and thereby the test conformed to ASTM C666.

298 The FRP hoop strains were monitored twice a day during the entire testing period for

299 specimens fitted with strain gauges. Two readings were made each day, one during the freeze

300 phase and the other during the thaw phase. The strains were measured throughout this period.

301 All strain gauges survived the freeze-thaw test. Figures $6 a$ and $6 \mathrm{~b}$ show the strain in the FRP

302 wraps during the freeze-thaw cycles for GFRP and CFRP, respectively. In general, the strain

303 during the freeze cycle was $100-200 \mu \varepsilon$ higher than that during the thaw cycle. This is most

304 likely due to the thermal contraction of the glass wrap during freezing. However, for carbon

305 there was only a slight difference between thaw and freeze readings since its coefficient of

306 thermal expansion is close to zero.

307 Compression Test: Figure 7 and Table 5 show results of the compression tests for round

308 and square wrapped specimens without and with freeze-thaw conditioning. All the FRP-

309 wrapped specimens were subjected to corrosion-like expansion simulated with Bristar, all

310 conditioned specimens were subjected to 300 cycles of freeze-thaw cycles, and control

311 specimens were not subjected to freeze-thaw cycles. None of the plain concrete specimens

312 were subjected to corrosion-like expansion simulated by Bristar. The following observations

313 are made:

314 - Plain round specimens: Only one of three specimens survived freeze-thaw conditioning

315 for 300 cycles. The two specimens that did not survive had extensive cracking and

316 spalling due to freeze-thaw cycles, which made it impossible to perform compression

317 testing on them. The specimen that survived had approximately the same compression 
318 strength as the control specimens $(\sim 35-45 \mathrm{MPa})$. There was no significant reduction in

319 strength due to freeze-thaw conditioning if the specimen survived.

320 - Round glass-wrapped specimens: In general, conditioning had little effect and the

321 compression strength was approximately the same for control and conditioned specimens.

322 The strength of wrapped specimens $(\sim 105-110 \mathrm{MPa})$ was approximately 2.6 times larger

323 than the strength of unwrapped specimens.

324 - Round carbon-wrapped specimens: Conditioning reduced the compression strength

325 from about $95 \mathrm{MPa}$ to about $80-94 \mathrm{MPa}$, generally representing about a $15 \%$ strength

326 loss. The strength of wrapped specimens ( $\sim 95 \mathrm{MPa})$ was approximately 2.3 times larger

327 than the strength of unwrapped specimens.

328 - Square glass-wrapped specimens: Again, conditioning had little effect on the 329 compressive strength $(\sim 62-66 \mathrm{MPa})$. The strength of wrapped specimens was 330 approximately 1.5 times larger than the strength of unwrapped specimens.

331 - Square carbon-wrapped specimens: Conditioning reduced the compression strength 332 slightly from about 58-65 $\mathrm{MPa}$ to about 55-63 MPa. The strength of wrapped specimens $333(\sim 60 \mathrm{MPa})$ was approximately 1.4 times larger than the strength of unwrapped $334 \quad$ specimens.

335 The wrapped square prisms had lower compressive strength compared to the wrapped

336 round cylinders, even though the cross sectional area of the prisms was higher than that of

337 the cylinders. This was due to the reduced confinement provided by the wraps for square 338 cross sections and stress concentrations that develop at the corners. For square prisms, glass

339 and carbon wraps increased the strength by about the same amount. Wrapped square prisms 340 always failed by rupture of the wrap at a corner. A reduction in compression strength of 
341 approximately $30-40 \%$ was observed between the round cylinders and the square prisms. The

342 wrapped square prisms also demonstrated a sudden loss of strength after the peak stress was

343 reached. However, the wraps were undamaged during this loss of strength. The loss of

344 strength was most likely due to the failure of the ineffectively confined regions of concrete.

345 These regions do not experience capacity enhancement due to poor confinement.

346 Table 5 shows the mean ultimate compression strengths and $95 \%$ confidence margins

347 for each category of specimens. The cross sectional area lost by the cavity containing Bristar

348 was deducted when calculating the strengths. At the $95 \%$ confidence level, means of the

349 compressive strength of specimens subjected to freeze-thaw cycles are not significantly

350 different from those of control specimens. Similarly, the freeze-thaw cycles have no

351 statistically significant effect on the compressive strength of square prisms. The reduction in

352 mean compressive strength observed for carbon-wrapped specimens after freeze-thaw

353 conditioning is not statistically significant for the sample size used in this study.

\section{SUMMARY AND CONCLUSIONS}

356 Strength and durability tests were carried out on round cylinders and square prisms

357 made of concrete and wrapped with glass and carbon FRP. An expanding cement known as

358 Bristar was used in the wrapped specimens to investigate the durability of glass and carbon

359 wraps under sustained expansion load and subjected to freeze-thaw cycling. The sustained

360 expansion load simulated the load generated in wrapped columns by corrosion products.

361 Chloride was impregnated into the cylinders during casting in order to simulate concrete

362 exposed to salt. The compression strength of plain control cylinders as well as wrapped test 
363 specimens after 300 cycles of freeze-thaw conditioning was measured. A total of 60

364 specimens were used in the freeze-thaw test.

365 The means of the compressive strength of freeze thaw specimens were not

366 significantly different from those of control specimens at the $95 \%$ confidence level. This was

367 true both for carbon and glass wraps, and for specimens with round and square cross

368 sections. The results indicate that the wraps did not sustain significant damage due to freeze-

369 thaw cycling under sustained load.

370 The wrapped square prisms had lower compressive strengths compared to the

371 wrapped round cylinders, even though the cross sectional area of the square prisms was

372 higher than that of the round cylinders. This was due to the reduced confinement provided by

373 the wraps for square cross sections and stress concentrations that develop at the corners.

374 Wrapped square prisms always failed by rupture of the wrap at a corner. A reduction in the

375 failure strength of approximately $30-40 \%$ was observed for the square specimens compared 376 to the round specimens.

377 The compression strength of wrapped specimens was 1.4 to 2.6 times larger than that

378 of unwrapped specimens for square and round cross sections, respectively.

380 ACKNOWLEDGEMENTS

381 This research was sponsored by the Michigan Department of Transportation.

\section{REFERENCES}

384 Almusallam, T. H., Al-Salloume, Y. A., and Alsayed, S. H. (2000). "Durability of concrete 385 cylinders wrapped with GFRP sheets at different environmental conditioning." Seventh 
Arya, C., and Sa'id-Shawqi, Q. (1996). "Factors influencing electrochemical removal of chloride from concrete." Cement and Concrete Research, 26(6), 851-860.

Chajes, M.J., Mertz, D.R., and Thomson, T.A. (1994). "Durability of composite material reinforcement." Proceedings, Third Materials Engineering Conference, ASCE, San Diego, California.

Chin, J. W., Nguyen, T., and Aouadi, K. (1997). "Effects of environmental exposure on fiber-reinforced plastic (FRP) materials used in construction." Journal of Composites Technology and Research, 19(4), 205-213,

Colombi, P., Fava. G. and Poggi, C., (2010). "Bond strength of CFRP-concrete elements under freeze-thaw cycles." Composite Structures, 92(4), 973-983.

Du, Y. G., Chan, A. H. C., and Clark, L.A (2006). "Finite element analysis of the effects of radial expansion of corroded reinforcement." Computers and Structures, 84(13-14), 917929.

El-Zefzafy, H., Mohamed, H. M., and Masmoudi, R. (2011). "Freeze-thaw effects on the behavior of concrete-filled FRP tube columns." Proceedings, Annual Conference of the Canadian Society for Civil Engineering, 2, 1563-1572.

Gomez, J., and Casto, B. (1996). "Freeze-thaw durability of composite materials." Proceedings, 1st International Conference on Composites in Infrastructure (ICCI), Tucson, AZ, 947-955.

Green, M. F., Bisby, L. A., Fam, A. Z., and Kodur, V. K. (2006). "FRP confined concrete columns: behaviour under extreme conditions." Cement and Concrete Composites, 28(10), 928-937.

Harichandran, R. S., and Baiyasi, M. I. (2000). "Repair of corrosion-damaged columns using FRP wraps." Report No. RC-1386, Michigan Department of Transportation, Lansing, Michigan.

Karbhari, V. M. and Zhao, L., (1998). "Issues related to composite plating and environmental exposure effects on composite-concrete interface in external strengthening." Composite Structures, 40(3/4), 293-304.

Li, Y., and Karbhari, V. M. (2003). "Durability characterization of T700 based composites for use in civil infrastructure." Proceedings, $44^{\text {th }}$ International SAMPE Symposium and Exhibition, Vol. II, 1540-1552. 
Mehta, P., and Monteiro, J. (1993). Concrete, structure, properties, and materials. Second Edition, Prentice-Hall, Englewood Cliffs, 160-164.

Nardone, F., Di Ludovico, M., De Caso Y., Basalo, F. J., Prota, A., and Nanni, A. (2012). "Tensile behavior of epoxy based FRP composites under extreme service conditions." Composites Part B: Engineering, 43(3), 1468-1474.

Rivera, J., and Karbhari, V. (1999). "Effects of extended freeze-thaw exposure on composite wrapped concrete cylinders." Proceedings, $44^{\text {th }}$ SAMPE Symposium, Long Beach, California, May 23-27.

Shi, J., Zhu, H., Wu, Z., Seracino, R., and Wu, G. (2013). "Bond behavior between basalt fiber-reinforced polymer sheet and concrete substrate under the coupled effects of freezethaw cycling and sustained load." Composites in Construction, 17(4), 530-542.

Silva, M. A. G, and Biscaia, H. (2008). "Degradation of bond between FRP and RC beams." Composite Structures, 85(2), 164-174.

Soudki, K. A. (1997). "Freeze-thaw response of CFRP wrapped concrete." Concrete International, 19(8), 64-67.

Steckel, G. L., Hawkins, G. F., and Bauer, J. L. (1998). "Environmental durability of composites for seismic retrofit of bridge columns." $2^{\text {nd }}$ International Conference on Fiber Composites in Infrastructure ICCI, Vol.2, Tucson, 460-475.

Toutanji, H., and Balaguru, P. (1998). "Durability characteristics of concrete columns wrapped with FRP tow sheets." Journal of Materials in Civil Engineering, 10(1), 52-57.

Toutanji, H., and El-Korchi, T. (1999). "Tensile durability of cement-based FRP composite wrapped specimens." Journal of Composites for Construction, ASCE, 3(1), 38-45.

Yu, T., Teng, J. G., Wong, Y. L., and Dong, S. L. (2010). "Finite element modeling of confined concrete-I: Drucker-Prager type plasticity model." Engineering Structures, 32(3), 665-679.

Yun, Y., and Wu, Y. F. (2011). "Durability of CFRP-concrete joints under freeze-thaw cycling." Cold Reg. Sci. Technol., 65(3), 401-412. 
Table 1: Freeze-Thaw Laboratory Testing Matrix

\begin{tabular}{|c|c|c|c|c|}
\hline \multirow{2}{*}{$\begin{array}{c}\text { Specimen } \\
\text { Type }\end{array}$} & \multirow{2}{*}{ Conditioning } & \multicolumn{3}{|c|}{ No. of Specimens } \\
\cline { 3 - 5 } & & Unwrapped & GFRP & CFRP \\
\hline Round & \multirow{2}{*}{ None } & 3 & 3 & 3 \\
Square & & 3 & 3 & 3 \\
\hline Round & \multirow{2}{*}{300 cycles of freeze-thaw } & \multirow{2}{*}{3} & 3 & 3 \\
Square & & & 3 \\
\hline
\end{tabular}

473

474 
475

476

477

478

479

480

481

482

483

484
Table 2: Analytical Estimate of Maximum Confining Pressure and GFRP Strain

\begin{tabular}{|c|c|c|c|}
\hline $\begin{array}{c}\text { Water/Bristar } \\
\text { Ratio }\end{array}$ & $\begin{array}{c}\text { Measured Strain } \\
(\boldsymbol{\mu} \boldsymbol{\varepsilon})\end{array}$ & $\begin{array}{c}\text { Confining } \\
\text { Pressure (MPa) }\end{array}$ & $\begin{array}{c}\text { Strain in } \\
\text { GFRP }(\boldsymbol{\mu} \boldsymbol{\varepsilon})\end{array}$ \\
\hline 0.5 & 380 & 4.76 & 4500 \\
\hline 0.4 & 660 & 8.27 & 7800 \\
\hline
\end{tabular}


Table 3: Parameters used in FE Analysis

\begin{tabular}{|c|c|c|c|c|}
\hline Materials & $\begin{array}{c}\text { Elastic Modulus } \\
\text { (GPa) }\end{array}$ & $\begin{array}{c}\text { Strength } \\
\text { (MPa) }\end{array}$ & $\begin{array}{c}\text { Thickness } \\
\text { (mm) }\end{array}$ & $\begin{array}{c}\text { Poisson's } \\
\text { Ratio }\end{array}$ \\
\hline Concrete & 28.8 & $\begin{array}{c}\text { (Compressive) } \\
37.7\end{array}$ & NA & 0.16 \\
\hline Steel & 200.0 & 410.0 & 4.77 & 0.3 \\
\hline GFRP & $\begin{array}{c}\text { (Fiber direction) } \\
27.6\end{array}$ & NA & 1.00 & 0.29 \\
\hline
\end{tabular}

495 
Table 4: Mechanical Properties of FRP Panels Before and After Freeze-Thaw Exposure

\begin{tabular}{|c|c|c|c|c|c|}
\hline $\begin{array}{c}\text { Wrap } \\
\text { Type }\end{array}$ & $\begin{array}{c}\text { Thickness } \\
(\mathbf{m m})\end{array}$ & $\begin{array}{c}\text { Modulus } \\
(\mathbf{M P a})\end{array}$ & $\begin{array}{c}\text { Effective } \\
\text { Stiffness } \\
\mathbf{( N / m m )}\end{array}$ & $\begin{array}{c}\text { Ultimate } \\
\text { Strength per } \\
\text { Unit Width } \\
\mathbf{( N / m m )}\end{array}$ & $\begin{array}{c}\text { Ultimate } \\
\text { Strain }\end{array}$ \\
\cline { 2 - 6 } & & \multicolumn{5}{|c|}{ No Exposure } \\
\hline GFRP & 1.227 & 22,011 & 27,000 & 536 & 0.02 \\
\hline CFRP & 0.625 & 53,061 & 33,150 & 415 & 0.015 \\
\hline & & \multicolumn{5}{|c|}{ 300 Freeze-Thaw Cycles } \\
\hline GFRP & 1.092 & 23,805 & 26,000 & 424 & 0.016 \\
\hline CFRP & 0.508 & 79,012 & 40,138 & 448 & 0.01 \\
\hline
\end{tabular}

497

498 
Table 5: Compression Test Summary Data

\begin{tabular}{|c|c|c|c|c|c|}
\hline \multicolumn{3}{|c|}{ Specimens Type } & \multicolumn{3}{|c|}{ Ultimate Compressive Strength (kPa) } \\
\hline Wrap & Shape & Condition & Average & $\begin{array}{l}\text { Standard } \\
\text { Deviation }\end{array}$ & $\begin{array}{l}\text { 95\% Conf. } \\
\text { Margin }\end{array}$ \\
\hline \multirow{2}{*}{ No Wrap } & \multirow{2}{*}{ Round } & Control & 41,074 & 2,531 & $\pm 2,656$ \\
\hline & & $\mathrm{F} / \mathrm{T}$ & 42,875 & NA & NA \\
\hline \multirow{4}{*}{ GFRP } & \multirow{2}{*}{ Square } & Control & 63,601 & 1,907 & $\pm 2,002$ \\
\hline & & $\mathrm{F} / \mathrm{T}$ & 63,761 & 1,208 & $\pm 3,002$ \\
\hline & \multirow{2}{*}{ Round } & Control & 109,911 & 3,856 & $\pm 6,136$ \\
\hline & & $\mathrm{F} / \mathrm{T}$ & 108,370 & 1,727 & $\pm 4,291$ \\
\hline \multirow{4}{*}{ CFRP } & \multirow{2}{*}{ Square } & Control & 91,924 & 2,652 & $\pm 2,783$ \\
\hline & & $\mathrm{F} / \mathrm{T}$ & 59,384 & 3,149 & $\pm 7,822$ \\
\hline & \multirow{2}{*}{ Round } & Control & 92,558 & 3,612 & $\pm 3,791$ \\
\hline & & $\mathrm{F} / \mathrm{T}$ & 84,714 & 8,440 & $\pm 20,967$ \\
\hline
\end{tabular}

500

501

502

503

504

505

506

507

508

509

510

511

512

513 


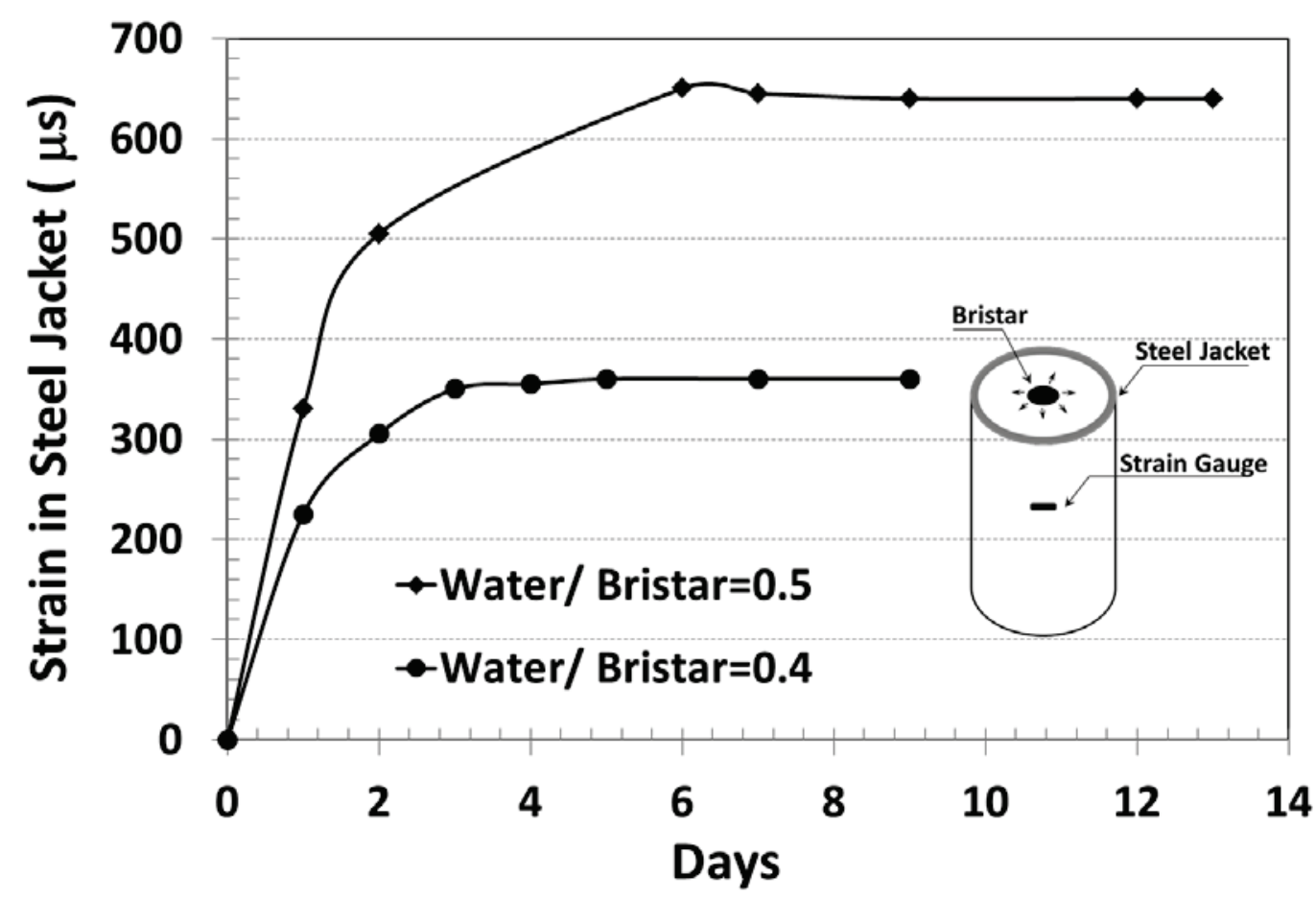

514

515

516

517

518

519

520

521

522

Figure 1: Strain in steel tube for different water to Bristar ratios 
543

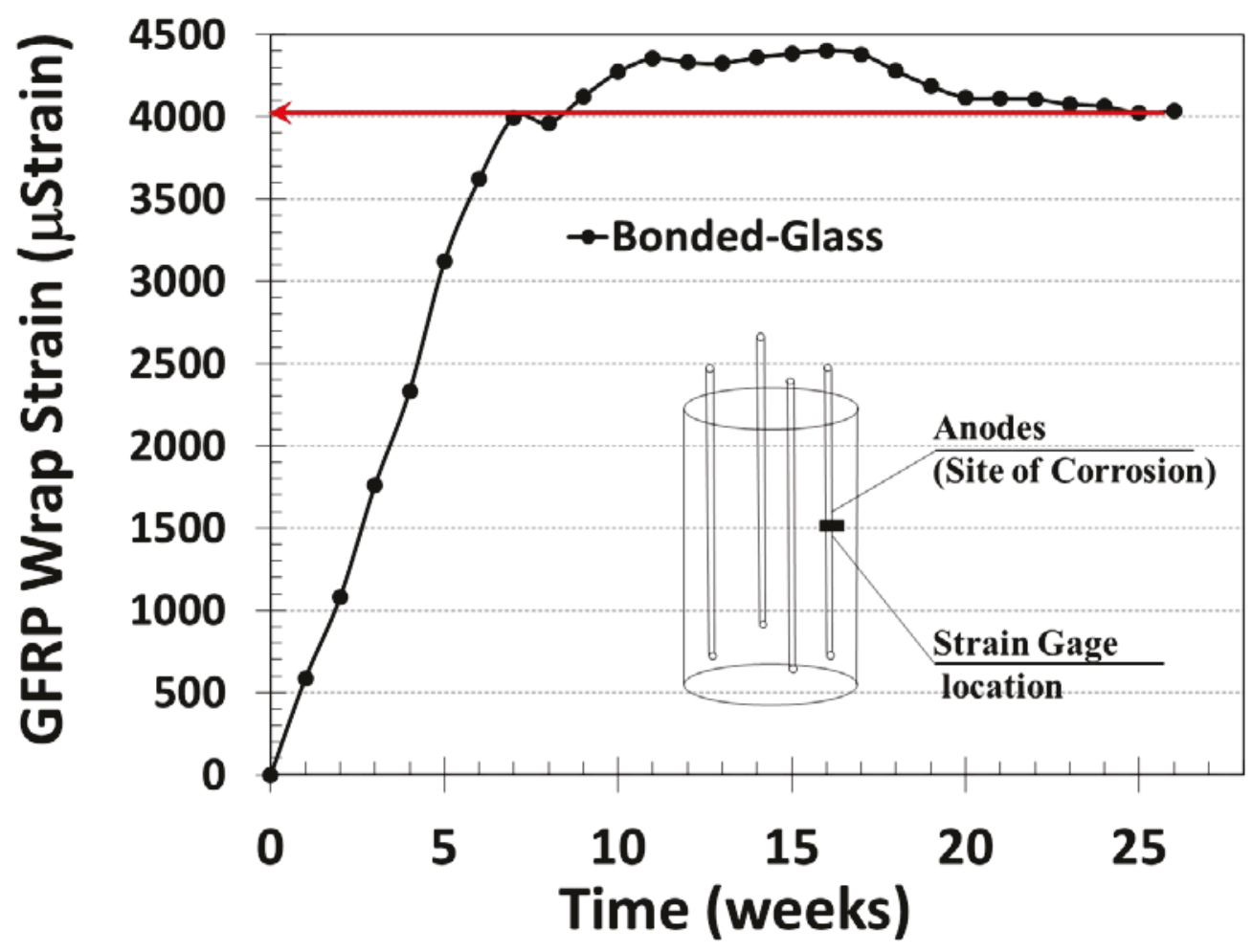

Figure 2: Strain developed in GFRP wrap in accelerated corrosion test (Harichandran and Baiyasi 2000) 


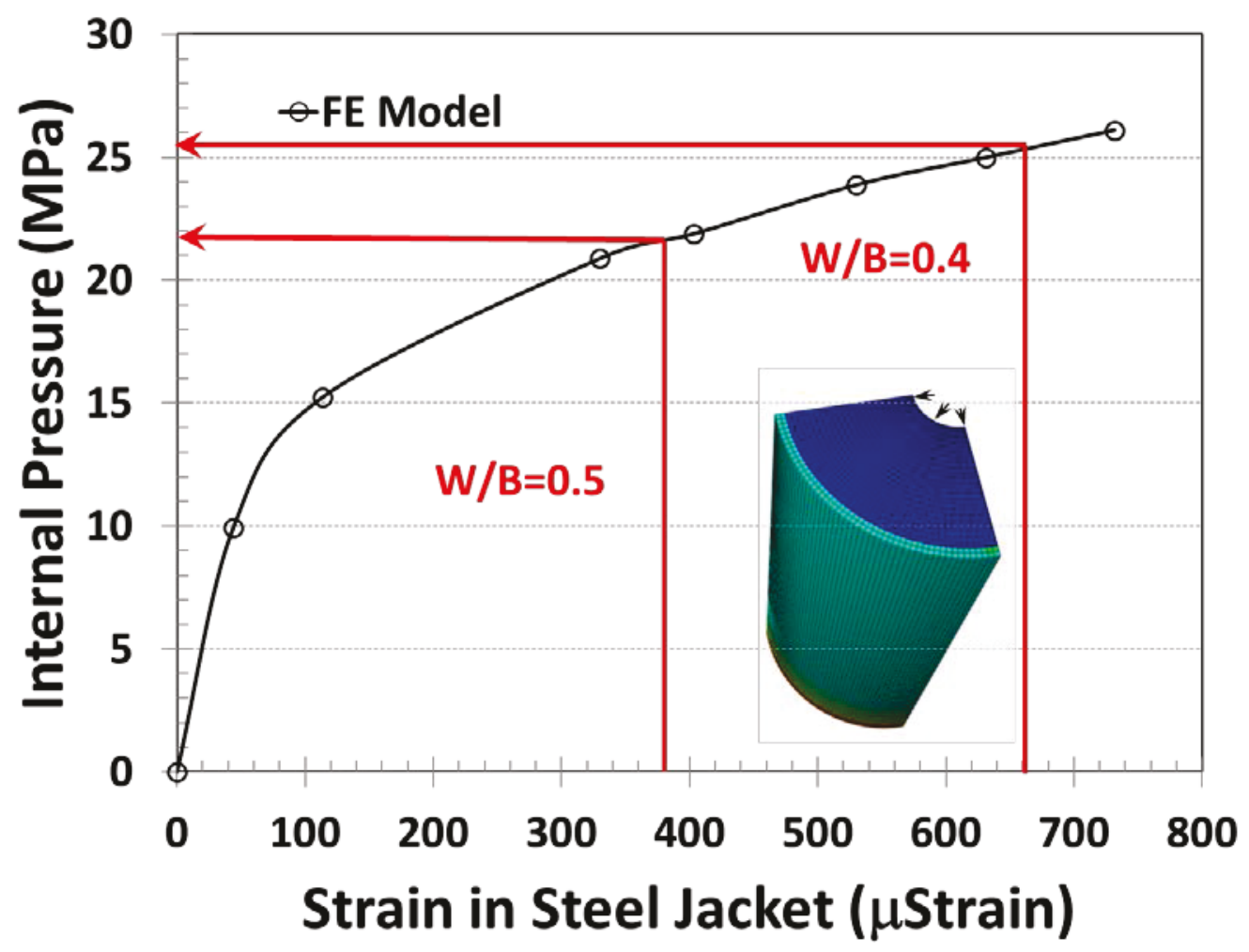

Figure 3: Strain developed in steel tube in FE model of calibration specimens 


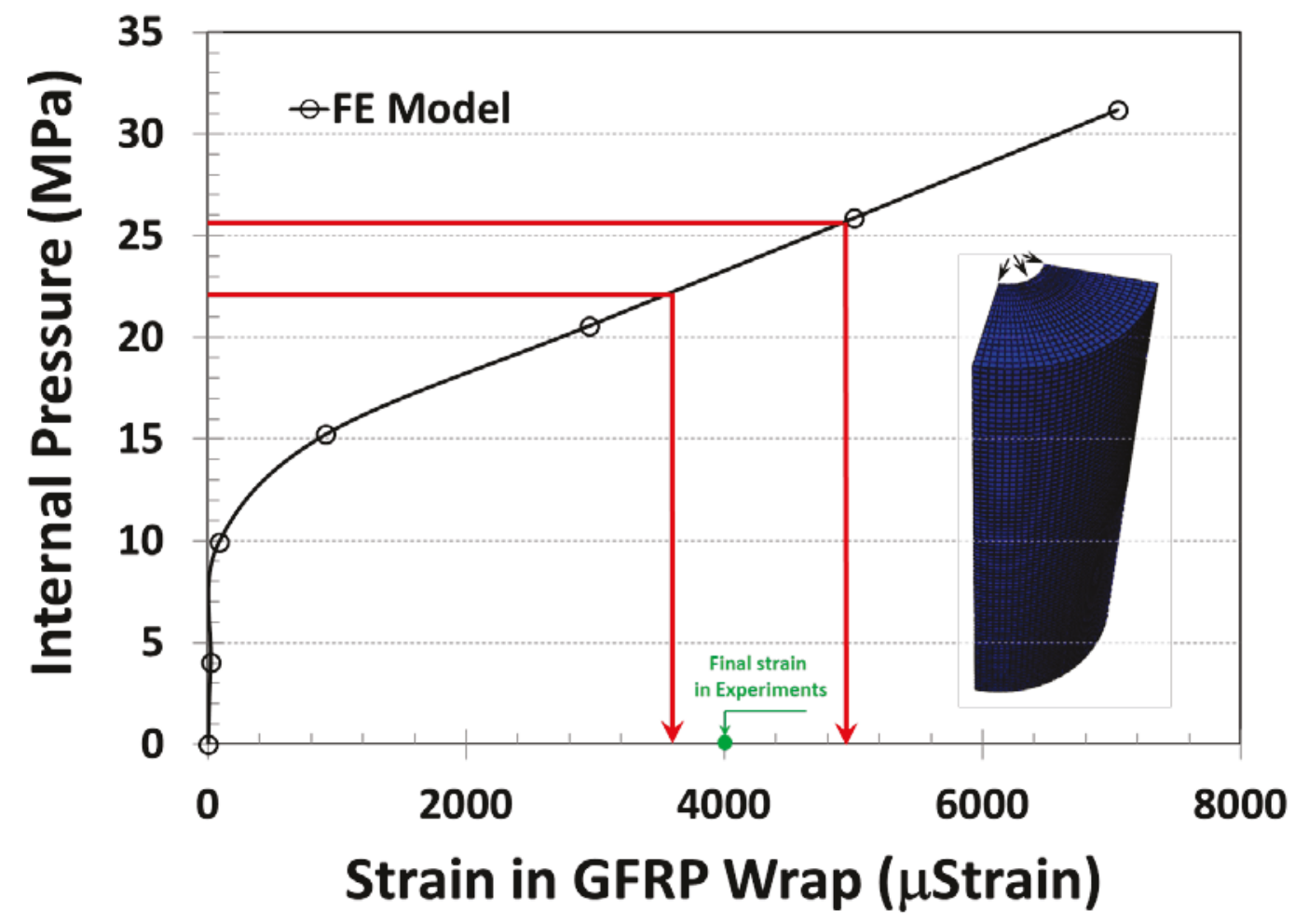

Figure 4: Strain developed in GFRP wrap in FE model of test specimens 


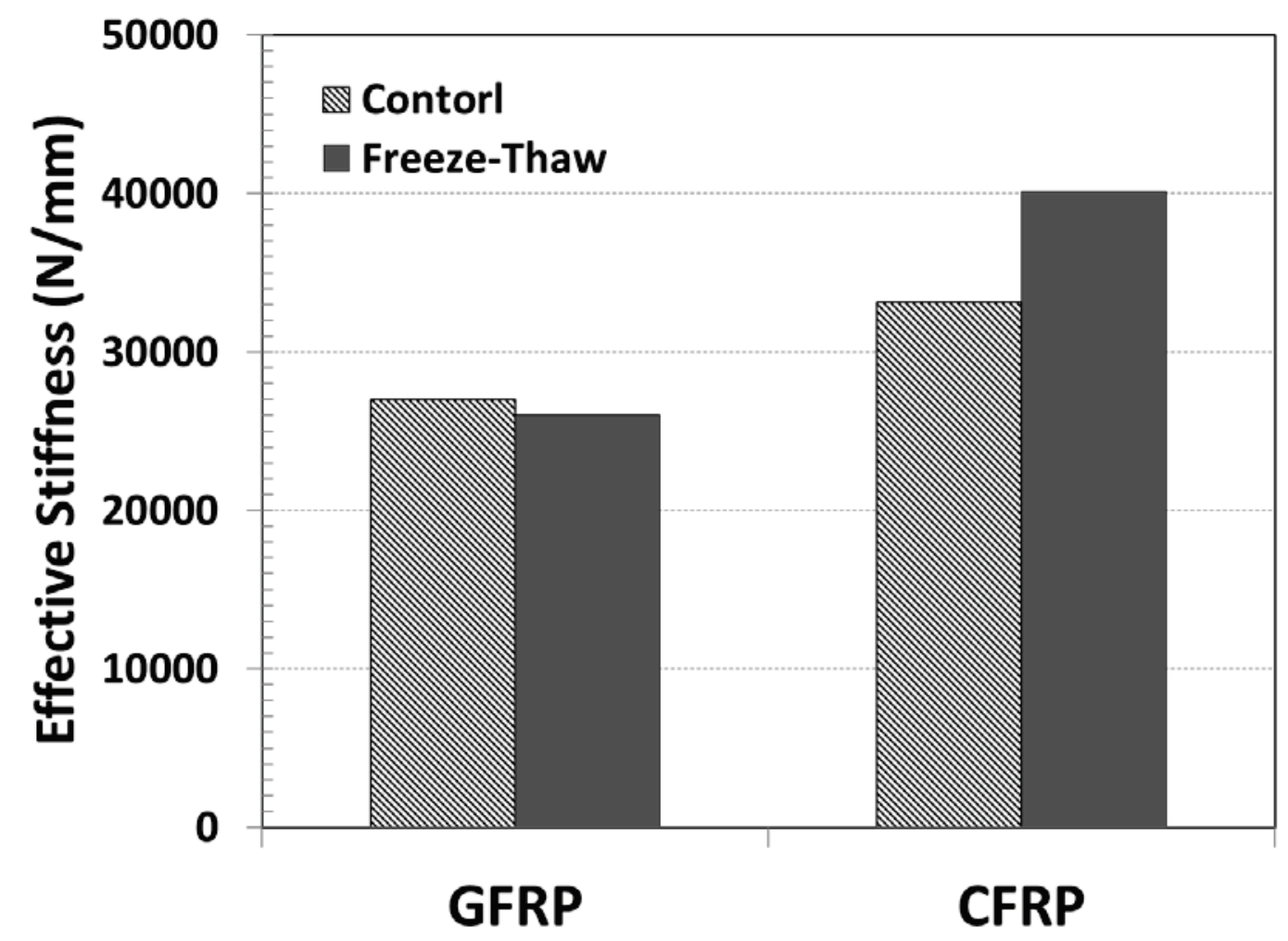

594

595

596

597

Figure 5: Effective stiffness of FRP panels after 300 freeze-thaw cycles

598

599

600

601

602

603

604

605

606

607

608

609

610

611

612

613

614

615

616

617 
618

619

620

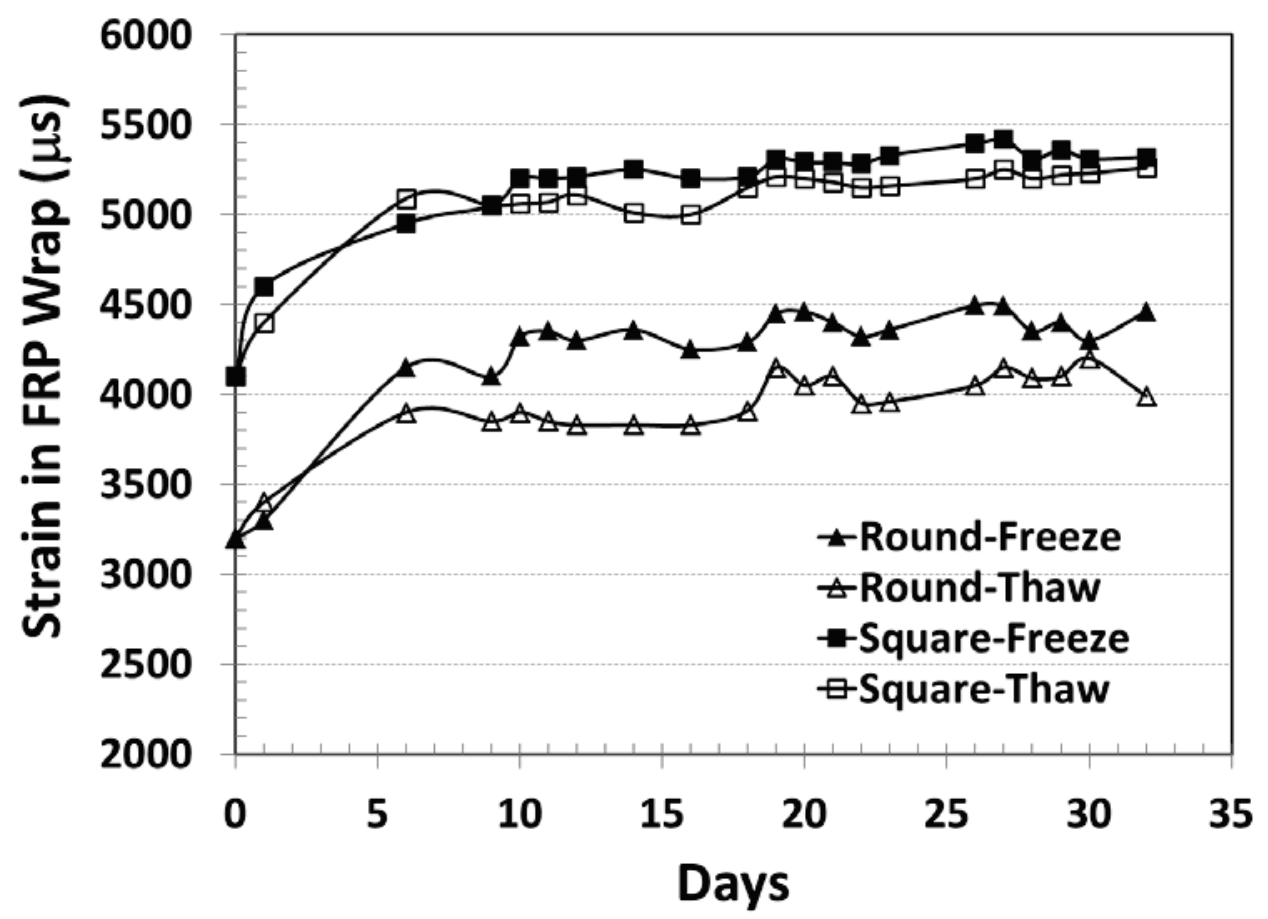

(a)

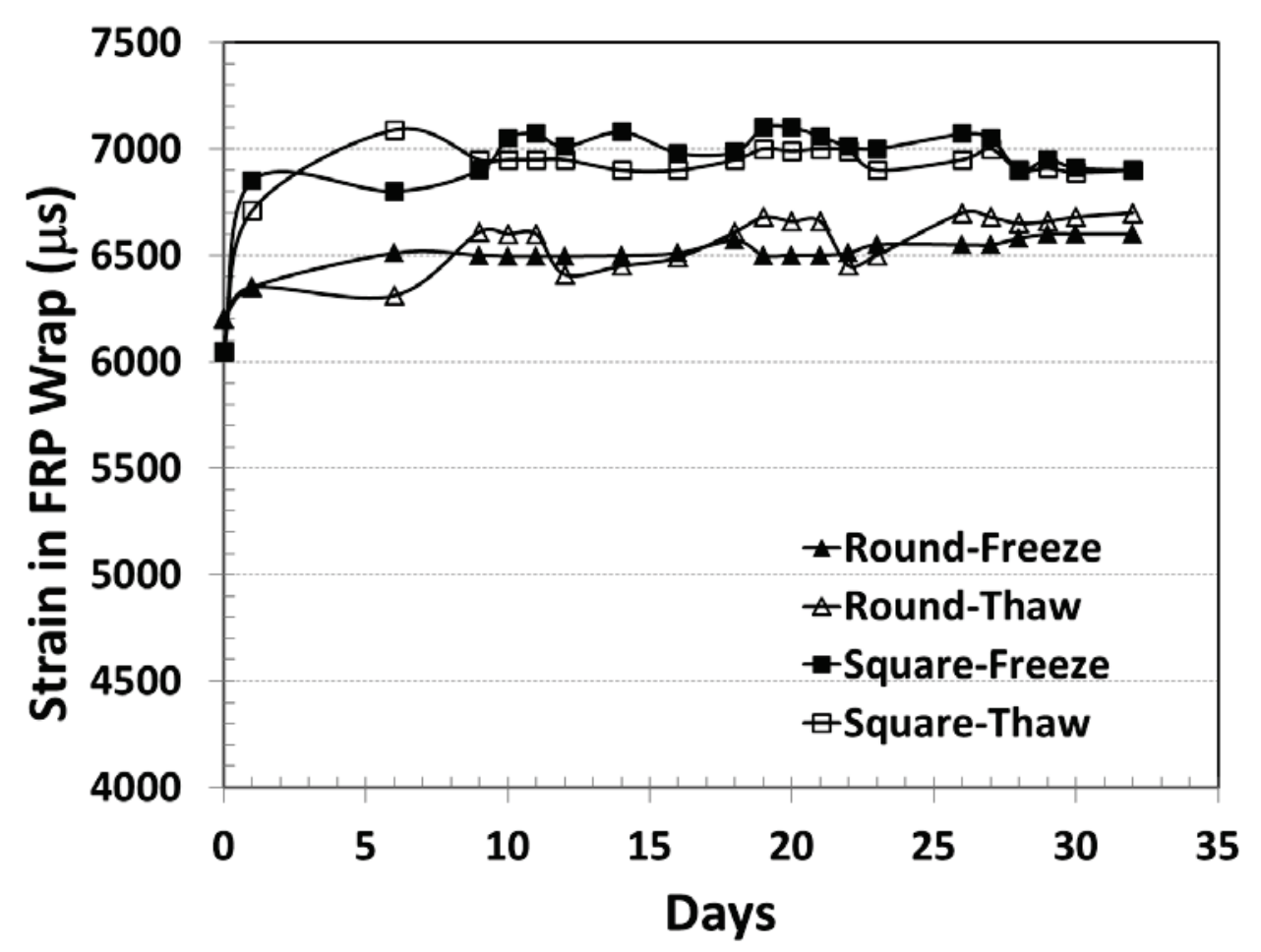

(b)
621

622

623

624

625

Figure 6: Strain in FRP wrap during freeze-thaw cycles (a) glass, (b) carbon 
626

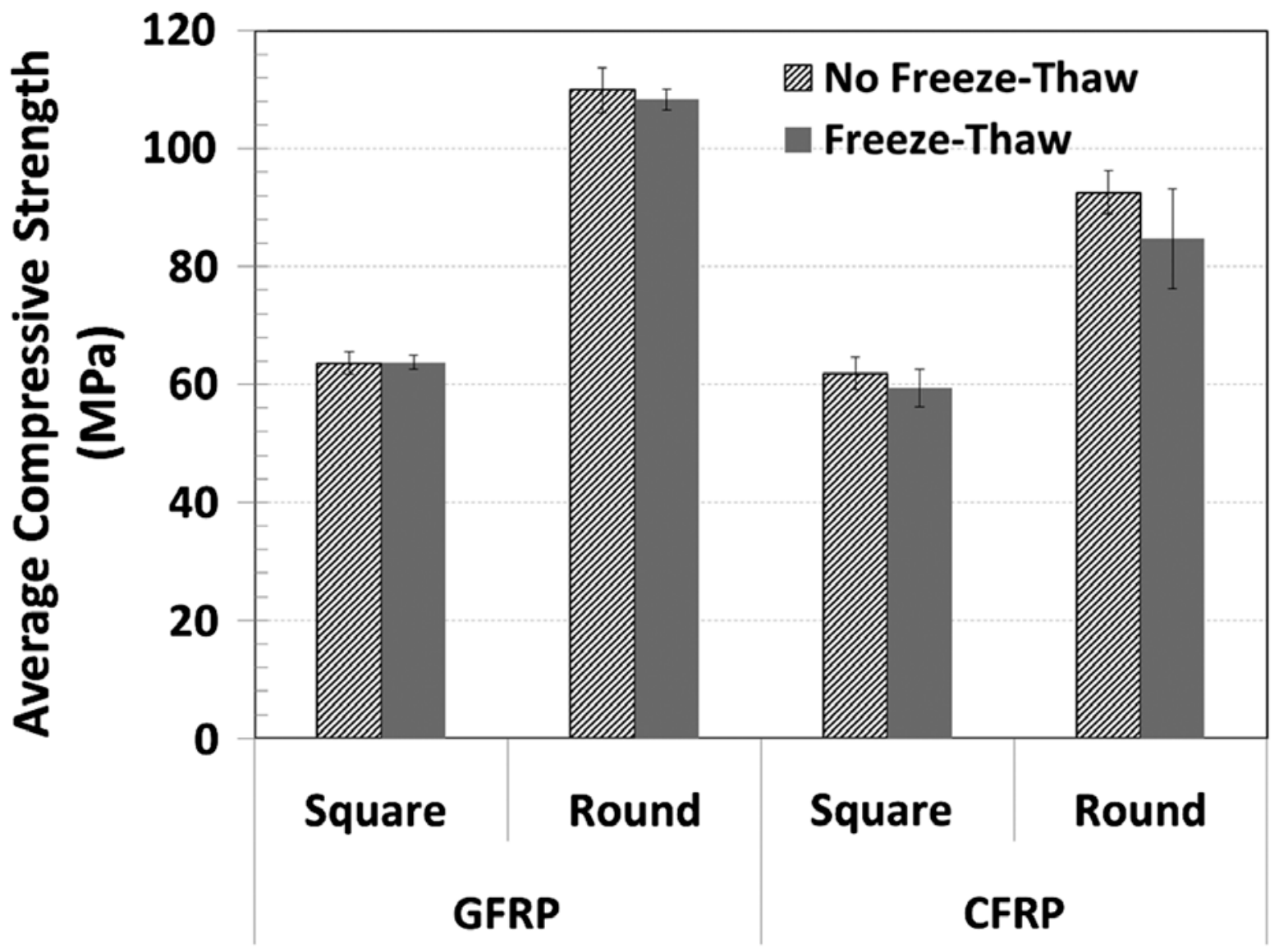

628

629

630

Figure 7: Results of the compression tests for round and square wrapped specimens

631 